\title{
Neuro-angiostrongylosis in wild Black and Grey-headed flying foxes (Pteropus spp)
}

\author{
JL BARRETT ${ }^{\mathrm{a}}$, M S CARLISLE ${ }^{\mathrm{b}}$ and P PRO CIV ${ }^{\mathrm{c}}$
}

\begin{abstract}
Objective To identify nematodes seen in histological sections of brains of flying foxes (fruit bats) and describe the associated clinical disease and pathology.
\end{abstract}

\begin{abstract}
Proceedures Gross and histological examination of brains from 86 free-living flying foxes with neurological disease was done as part of an ongoing surveillance program for Australian bat lyssavirus. Worms were recovered, or if seen in histological sections, extracted by maceration of half the brain and identified by microscopic examination. Histological archives were also reviewed.
\end{abstract}

Results There was histological evidence of angiostrongylosis in 16 of 86 recently submitted flying foxes with neurological disease and in one archival case from 1992. In 10 flying foxes, worms were definitively identified as Angiostrongylus cantonensis fifth-stage larvae. A worm fragment and third stage larvae were identified as Angiostrongylus sp, presumably $A$ cantonensis, in a further three cases. The clinical picture was dominated by paresis, particularly of the hindlimbs, and depression, with flying foxes surviving up to 22 days in the care of wildlife volunteers. Brains containing fifthstage larvae showed a moderate to severe eosinophilic and granulomatous meningoencephalitis $(n=14)$, whereas there was virtually no inflammation of the brains of bats which died when infected with only smaller, third-stage larvae $(n=3)$. There was no histological evidence of pulmonary involvement.

Conclusion This is the first report of the recovery and identification of $A$ cantonensis from free-living Australian wildlife. While angiostrongylosis is a common cause of paresis in flying foxes, the initial clinical course cannot be differentiated from Australian bat lyssavirus infection, and wildlife carers should be urged not to attempt to rehabilitate flying foxes with neurological disease.

Aust Vet J 2002;80:554-558

$\begin{array}{ll}\text { CNS } & \text { Central nervous system } \\ \text { HE } & \text { Haematoxylin and eosin }\end{array}$

$\mathrm{T}$

he rat lungworm, Angi ostrongylus cantonensis, is a metastrongylid nematode that inhabits the right ventricle and pulmonary arteries of various rats, being restricted in Australia to the two introduced species, Rattus norvegicus and $R$ rattus. Since its lifecycle was elucidated in Brisbane almost 50 years ago, ${ }^{1}$ it has been incriminated in infections in a wide range of mammalian hosts, ${ }^{2}$ almost all presenting with disease of the $\mathrm{CN}$ S. O riginally, cases were reported in coastal Q ueensland and north-eastern $\mathrm{N}$ ew South Wales, although, over the last decade, the parasite has been recognised in Sydney in dogs, rats, zoo

\footnotetext{
animal Research Institute, 665 Fairfield Rd Yeerongpilly Queensland 4105 bIDEXX/Veterinary Pathology Services, East Brisbane Queensland 4169

${ }^{\mathrm{C}}$ Department of Microbiology and Parasitology, The University of Queensland Queensland 4072
}

primates and native mammals.2

Rats, and abnormal definitive hosts, acquire the infection by eating third stage larvae in the tissues of the intermediate hosts, slugs and snails, which have become infected by eating firststage larvae expelled in rat faeces. M olluscivorous paratenic hosts (such as land planarians, freshwater crustacea) are sometimes infected, although their importance in Australia is unknown. 0 nce in the definitive host, infective larvae undergo an obligatory migration through the CN S, where they grow and moult twice to attain the immature adult stage. They then invade the venous system to return to the right ventricular outflow, where, in suitable hosts, they copulate and produce eggs. Clinical disease arises from mechanical damage and associated inflammation in nervous tissue, blood vessels and the subarachnoid space.

Recently, the parasite was reported for the first time in flying foxes (fruit bats), in captive Pteropus poliocephalus in Sydney. ${ }^{3}$ We have been aware for at least 9 years of the sporadic finding of nematodes in histological sections of brain from neurologically-affected captive and wild flying foxes in south-east Q ueensland and northern $\mathrm{N}$ ew South Wales, although the identity of these parasites had never been established. H ere, we now report the first confirmed $A$ cantonensis infections among wild Black and Grey-headed flying foxes (Pteropus alecto and P poliocephalus, respectively) from this region.

\section{$M$ aterials and methods}

From N ovember 1997 to N ovember 2000, inclusive, 86 wild flying foxes with neurological signs were necropsied at the Queensland Department of Primary Industries Animal Research Institute, Yeerongpilly, as part of an ongoing surveillance program for Australian bat lyssavirus infection. They comprised $51 \mathrm{P}$ alecto, $24 \mathrm{P}$ poliocephalus, $9 \mathrm{P}$ scapulatus (Little Red flying fox) and $2 \mathrm{P}$ conspicillatus (Spectacled flying fox). For Iyssavirus detection, impression smears of fresh brain were fixed in acetone and subjected to a direct fluorescent antibody test using the $\mathrm{Centocor}^{\circledR}$ fluorescein-labelled anti-rabies reagent (Centocor Inc. M alvern, PA, USA). H alf the brain was then stored at $-70^{\circ} \mathrm{C}$, whereas the other half was fixed immediately in $10 \%$ buffered neutral formalin and processed for routine histology.

A worm recovered from the brain surface of one of the 86 flying foxes was fixed in $10 \%$ buffered neutral formalin for identification. $\mathrm{N}$ ematodes were seen histologically in brain sections of another 15 of the 86 flying foxes. The frozen halfbrains of these 15 bats were subsequently fixed at room temperature in $10 \%$ buffered neutral formalin, then gently macerated under stereomicroscopical guidance. All worms found were mounted in chlorlactophenol on a glass slide under a coverslip, examined by compound microscopy, drawn using a camera lucida attachment and measured. Formalin-fixed lungs, available from all except bat 7, were processed so that $\mathrm{HE}$-stained 
sections through the hilar regions could be examined microscopically for nematodes or eggs within the major pulmonary arterial branches.

$\mathrm{H}$ istological sections of the brain and lung of an additional specimen (bat 17) were retrieved from the archives of the Veterinary Pathology laboratory of The University of Q ueensland Veterinary School; fresh brain material was not available for lyssavirus testing, nor fixed tissue for worm extraction.

\section{Results}

The case details and clinical histories of 17 cases of neuroangiostrongylosis in flying foxes are shown in Table 1.

Bats 1-16 were negative for lyssaviruses by direct fluorescent antibody test; bat 17 was not tested.

\section{Gross pathological findings}

Ten of the 16 bats submitted to the Animal Research Institute, and bat 17, were well-nourished, with ample fat reserves. The conditions of bats 7 and 8 were poor, while those of bats 1, 2, 3 and 4 were not recorded. Bat 6 , maintained in care for 22 days, had considerable amounts of abdominal fat, but wasting of the pectoral muscles and brown discoloration of the meninges. Bat 3 had a retroperitoneal haemorrhage at the level of the left adrenal gland. Although no spinal fracture was detected grossly, the spinal column was removed for radiological examination, which revealed displacement of the caudal endplate of the third lumbar vertebra. Petechial hemorrhages were found on the cerebral cortices of bats 11, 12 and 13, whereas the meninges of bat 11 were congested, and the ventral meninges of bats 13 and 15 were cloudy. O ne nematode was recovered from the dorsal surface of the cerebellum and brain stem of bat 15 .

\section{H istopathology}

Eosinophilic and granulomatous meningoencephalitis, and one or more sections of nematodes, as shown in Figures 1 and 2, were found in brain sections from bats 1, 2, 5 to 13, 15, 16 and $17(n=14)$. The meningitis was typically most severe around the brain stem and cerebellum, with macrophages predominating in the infiltrate, often with large numbers of lymphocytes and eosinophils, some plasma cells, and occasionally, multinucleated giant cells. In all but one of the recent cases there were perivascular cuffs of macrophages, lymphocytes and eosinophils. T hese perivascular cuffs were particularly prominent in bats $1,2,7$, and 8 . Foci and tracts of tissue disruption, gliosis, and/or haemorrhage, presumably the result of larval migration, were seen in sections from 10 of the recent cases and were most severe in bats $5,6,11$, and 13 . N ematode sections were seen most frequently in the subarachnoid space of the cerebral sulci and/or cerebellar folds, but some were located within the cerebral cortex, thalamus, cerebellum, brain stem and lateral ventricles. Bats 3,4 , and $14(n=3)$ were distinct in that they displayed virtually no inflammation, and their brain parenchyma appeared unremarkable except for the occasional presence of very small nematodes, as shown in Figure 2 (insert).

$\mathrm{N}$ either nematodes nor their eggs were found in any lung sections.

\section{Identification of worms}

Worms recovered from bats $2,5,6,9$ to 13,15 and 16 ( $n=$ 10) were identified as fifth-stage (L5) larvae ('immature adults')
Table 1 Case details and clinical histories of 17 flying foxes with neuroangiostrongylosis.

\begin{tabular}{lll}
\hline Bat & Description & Month/year, place found and clinical history \\
\hline 1 & Black adult M & $\begin{array}{l}11 / 1997 \text { Cleveland. Found on ground, aged, } \\
\text { debilitated, persistent hind limb paresis, } \\
\text { passive disposition, killed } 7 \text { days later. }\end{array}$ \\
2 & Black adult M & $\begin{array}{l}11 / 1997 \text { Brisbane. Rescued from wire fence, } \\
\text { paresis, poor hind limb reflexes, killed } 3 \text { days }\end{array}$
\end{tabular}
later.

$3 \quad$ Black adult $\mathrm{M}$

11/1997 Nambour. Found under palm tree, flaccid paralysis all limbs with absent grip and placing reflexes, full bladder, incontinent, killed within 24 hours.

$4 \quad$ Black adult $\mathrm{M}$

11/1997 Deagon. Docile in tree on the foot path. Next day, 'frothing' at mouth, head tilt, unequal pupils, killed.

$5 \quad$ Grey adult M

05/1998 Ashgrove. Found on ground, put in tree, didn't move, rescued next day. No improvement over 7 days, killed.

6 Black juvenile M 06/1998 Bundamba. Hanging low in tree, docile, paresis, initially able to hang. In care 22 days, became recumbent, cranial nerves normal, poor hind limb reflexes, killed.

12/1998 Nerang. Found weak and uncoordinated on ground by dogs, killed by dog owner. 10/1999 Brisbane. Found in tree, crashed when attempted to fly, dehydrated, generalized paresis, died same day.

$9 \quad$ Black adult $F$

10/1999 Everton Park. Seen in tree, next day on ground, ascending hind limb paresis. Day 3 , delivered stillborn pup. Persistent paresis, then day 16 head tilt, head tremor, nystagmus, pallor, killed.

10 Grey adult M

10/1999 Broadbeach. Found on ground, hind limb paresis, depressed intermittent shiver ing, no improvement over 8 days, killed.

$11 \quad$ Black juvenile $\mathrm{F}$

05/2000 Clontarf. Captive born, released. 2 to 3 weeks later found depressed in tree near cage, easily captured, movements stiff and slow. Deteriorated over 24 hours, nystagmus, died.

12 Black adult $F \quad 05 / 2000$ Southport. Found on ground, depressed, wide based stance, drooped wings, ate well, day 3 recumbent, killed.

13 Black juvenile M 06/2000 Hope Is. Found on ground, deterio rated over 7 days, profoundly depressed, generalised paresis, nystagmus killed.

$14 \quad$ Black adult $F$ 06/2000 Southport. Seen on ground under palm tree, rescued next day, depressed, unable to hang, hind limb paresis, killed.

$15 \quad$ Grey adult

F 11/2000 Miami. Found low in bush, would not fly, docile. Hung with wide based stance, wings held loosely. By day 9 inappetent, depressed, killed

16 Black adult M 11/2000 Palm Beach. Found low on fence, rescued 3 days later, moribund, recumbent, no voluntary limb movement, killed.

$17 \quad$ Black adult $\mathrm{M}$ hang, tremors, Treated for suspected Pb poisoning. Day 15, depressed, respiratory distress, died.

Black $=$ Pteropus alecto (Black flying fox)

Grey = Pteropus poliocephalus (Grey-headed flying fox).

$\mathrm{M}=$ male, $\mathrm{F}=$ Female 


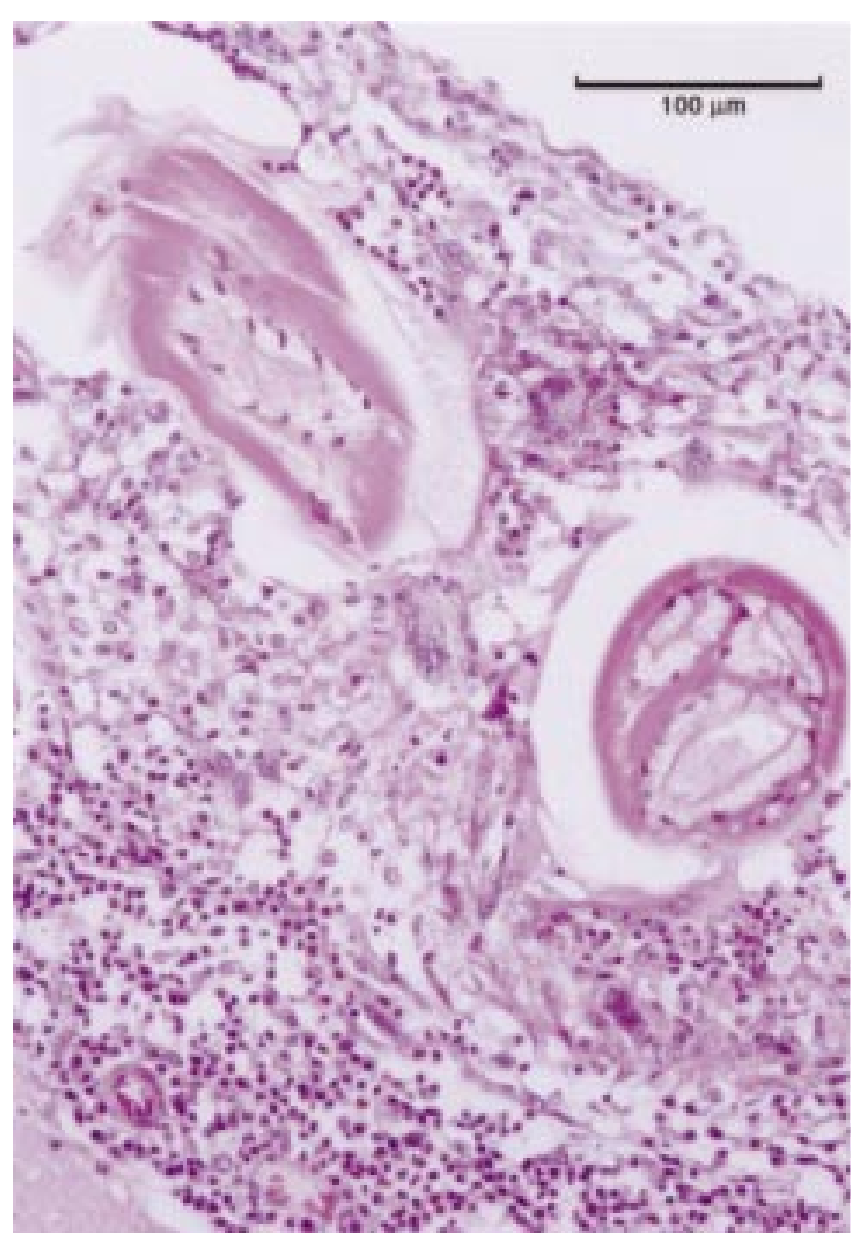

Figure 1. Female Angiostrongylus cantonensis (L5, maximum diameter $102 \mathrm{~mm}$ ) from bat 6 within a focus of granulomatous meningitis containing macrophages, lymphocytes, eosinophils, and multinucleated giant cells.

of A cantonensis, as distinct from A mackerrasae, by the relatively long spicules in the males $(0.65$ to $1.46 \mathrm{~mm})$ and absence of a caudal mucron in the females. A fragment of an adult worm consistent with Angiostrongylus was recovered from bat 8 . M ultiple third-stage larvae (L3) 420 to $565 \mu \mathrm{m}$ in length were recovered from bats 3 and 4 ; their identification as Angiostrongylus $L 3$ was based on the overall size and shape, internal morphology and dimensions, the buccal details (including a 'double spear') and tail shape. 1,4 Worms were not recovered from the brains of bats 1,7 , or 14 , whereas the brain of bat 17 was not available for examination. The number and lengths of worms recovered from each bat are shown in Table 2. The duration of infection was estimated by comparing the size of nematodes with published maximum growth rates in experimental rats. ${ }^{1}$ In retrospect, some of this data is known to be derived from $A$ mackerrasae, although the growth of A cantonensis in comparable stages is al most identical. ${ }^{4,5}$ It was assumed that growth rates in bats, presumably abnormal hosts, was less than or equal to the rate found in rats, the natural hosts.

\section{Discussion}

Previous reports of infection with A cantonensis were in humans, captive wildlife, or domestic animals. ${ }^{2}$ T his is the first report of $A$ cantonensis as a cause of disease in free living populations of Australian native wildlife in which the nematode has

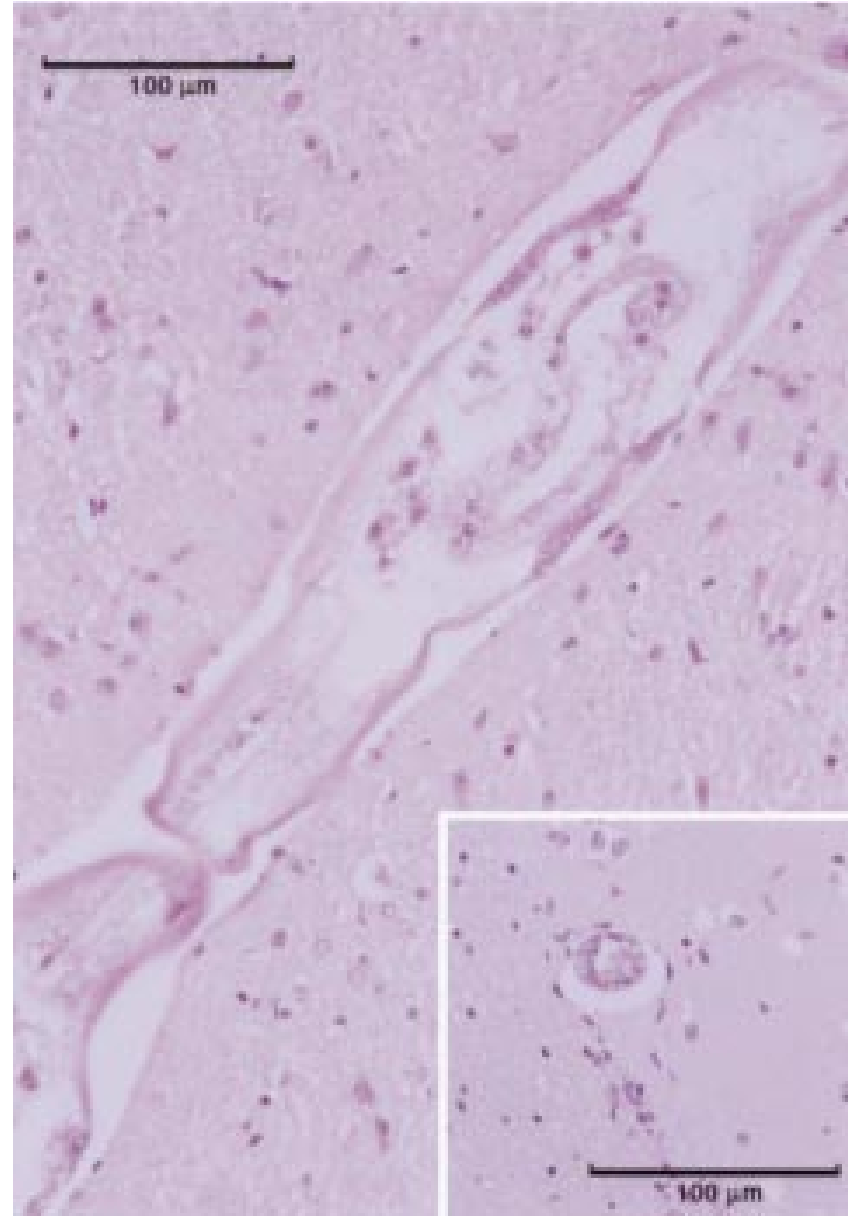

Figure 2. Angiostrongylus cantonensis (L5, maximum diameter $96 \mathrm{~mm}$ ) migrating through the thalamus of bat 11, as indicated by the absence of an adjacent inflammatory reaction. Severe granulomatous meningitis was seen elsewhere in this section in association with other worms. Insert is Angiostrongylus sp (L3, maximum diameter $29 \mathrm{~mm}$ ) in the frontal cortex of bat 14; early stage infection as indicated by immaturity of larva and lack of inflammatory response in the meninges and brain.

been recovered and identified. Between N ovember 1997 and N ovember 2000, of 86 flying foxes with CN S disease, 16 were diagnosed with neuro-angiostrongylosis (19\%), indicating this to be a common cause of neurological disease in flying foxes. $\mathrm{H}$ istological evidence of infection in another flying fox was also found in archival material from 1992. All the flying foxes with angiostrongylosis presented in south-east Queensland. $\mathrm{N}$ ematodes were recovered from the brains of 10 of the 16 recent cases, and morphologically confirmed as A cantonensis. The adult worm fragment and third stage larvae recovered from a further three cases, and histological sections of nematodes in the remaining three, had features consistent with those of Angiostrongylus spp, presumably A cantonensis. To date, only the introduced parasite, A cantonensis, not its native cogener, A mackerrasae, has been identified as a cause of disease in humans and animals. ${ }^{2}$

The number of cases involving Grey-headed compared to Black flying foxes ( 4 and 13 , respectively) reflects the relative numbers of these species in the study (24 and 51, respectively). W hereas the parasite was not identified in the Little red ( $P$ scapulatus) or Spectacled flying fox (P conspicillatus), this may 
Table 2. Numbers and lengths of Angiostrongylus cantonensis recovered from 16 free-living flying foxes and estimated duration of infection.

\begin{tabular}{|c|c|c|c|c|c|c|c|}
\hline \multirow[t]{2}{*}{ Bat } & \multicolumn{2}{|c|}{ Male worms } & \multicolumn{2}{|c|}{ Female worms } & \multirow{2}{*}{$\begin{array}{l}\text { Total worms } \\
\text { per half brain }{ }^{a}\end{array}$} & \multirow{2}{*}{$\begin{array}{c}\text { Time in care } \\
\text { (days) }\end{array}$} & \multirow{2}{*}{$\begin{array}{l}\text { Estimated duration } \\
\text { of infection }^{\mathrm{b}} \text { (days) }\end{array}$} \\
\hline & No. & Length (mm) & No. & Length (mm) & & & \\
\hline 1 & 0 & - & 0 & - & 0 & 7 & - \\
\hline 2 & 1 & 3.5 & 0 & - & 1 & 3 & 16 \\
\hline 3 & $?$ & - & $?$ & - & $11^{c}$ & 1 & $2-3$ \\
\hline 4 & $?$ & - & $?$ & - & $7^{c}$ & 1 & $2-3$ \\
\hline 5 & 2 & 4.2 and 6.0 & 14 & $4.5-15.4$ & 16 & 7 & 34 \\
\hline 6 & 9 & $4.4-7.2$ & 11 & $3.9-9.7$ & 20 & 22 & 24 \\
\hline 7 & 0 & - & 0 & - & 0 & 1 & - \\
\hline 8 & $?$ & - & $?$ & - & 1 (piece) & 1 & - \\
\hline 9 & 7 & $3.9-8.9$ & 7 & $8.6-10.1$ & 14 & 16 & 25 \\
\hline 10 & 3 & $3.9-4.3$ & 5 & $4.4^{d}$ & 8 & 8 & 18 \\
\hline 11 & 8 & $2.9-5.0$ & 12 & $3.6-4$ & 20 & 1 & 19 \\
\hline 12 & 12 & $2.6-5.1$ & 19 & $2.6-4.7$ & 31 & 3 & 19 \\
\hline 13 & 26 & $4.4-9.2$ & 14 & $6.8-11.0$ & 43 & 7 & 27 \\
\hline 14 & 0 & - & 0 & - & 0 & 1 & - \\
\hline 15 & - & - & $1^{e}$ & 8.8 & 1 & 9 & 23 \\
\hline 16 & 2 & 2.3 and 2.9 & 1 & 2.2 & 3 & 3 & 14 \\
\hline
\end{tabular}

aTotal number derived from intact specimens plus pieces recovered.

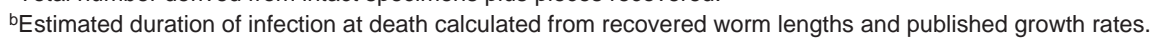

cImmature third stage larvae 420 to $565 \mu \mathrm{m}$ long, sex differentiation not possible.

dOnly one could be measured.

eSingle female worm recovered from brain surface, worms not extracted from fixed brain.

simply reflect their small numbers in the study (10 and 2, respectively). $\mathrm{H}$ istological evidence of Angiostrongylus sp has been reported in $\mathrm{P}$ scapulatus from Q ueensland. ${ }^{3}$ The presumptive finding of this parasite in histological sections from 1992 (bat 17) suggests that it has been affecting flying foxes for some time. Surveillance of flying foxes has intensified since they were linked with $\mathrm{H}$ endra virus (previously equine morbillivirus), and the discovery of Australian bat lyssavirus. Given the scanty material available from flying foxes before 1996, it is not possible to conclude that the apparently high number of cases described here reflects a changing prevalence of angiostrongylosis.

Presumably, flying foxes acquire infection by ingesting intermediate or paratenic hosts, such as slugs, snails and planarians, or their slime (although slime has still not been confirmed to be a vehicle of infection). ${ }^{2}$ These hosts could readily be concealed among fruit. While it might seem unlikely that flying foxes would eat these invertebrates, faecal analysis has shown that flying foxes regularly ingest insects, spiders and mites. ${ }^{6}$ Slugs and snails do climb high into trees, especially in wet weather $(P$ Prociv unpublished observation), and might either prove attractive to a hungry flying fox, or be ingested unintentionally.

C ontinuing habitat destruction in south-east Q ueensland has been linked to a reduction in flying fox numbers and fragmentation of their colonies, with the establishment of smaller, more numerous colonies in urban areas. ${ }^{7} \mathrm{H}$ abitat destruction, with overgrowth of introduced plant species, could force hungry flying foxes to eat unusual foods, such as molluscs. When food is scarce, flying foxes will retrieve fallen fruit from the ground, thus increasing their risk of ingesting molluscs. H owever, the good nutritional condition of 11 of the 17 cases suggests these bats had not had difficulty finding food. The circumstances and climatic conditions under which the flying foxes acquired the parasite are unknown, because infection might have occurred considerable distances from where they were found. Black flying foxes in urban south-east Q ueensland typically fly up to $7 \mathrm{~km}$ per night to feed (N M arkus personal communication) and also migrate considerable distances ( $>100 \mathrm{~km}$ during 10 weeks) to find native fruit and flowering trees. ${ }^{8}$ Grey-headed flying foxes from northern NSW have been shown to fly even greater distances each night (up to $50 \mathrm{~km}$ ) and seasonally (in excess of $600 \mathrm{~km}) .{ }^{9}$ D uring the 3 years of the study, cases were clustered in the months of April-June or 0 ctober-D ecember. It is possible that during these months, particular trees that are in flower or fruit attract both flying foxes and molluscs, bringing these species together. Four captive Grey-headed flying foxes with angiostrongylosis from Sydney also presented during $M$ ay and June, ${ }^{3}$ but this coincidence should be interpreted cautiously as the factors leading to infection of captive flying foxes in temperate Sydney might differ from those for free-living flying foxes in subtropical Q ueensland.

In each bat, worms were likely to have died before necropsy and fixation of the brain, and the worm lengths as measured are almost certainly accurate. Worm growth rates in flying foxes might differ from those in their normal definitive hosts. N evertheless, assuming growth rates less than or equal to the rate in rats, the estimated duration of infection in some of the cases all ows for interesting conclusions. Three flying foxes (bats 3, 4 and 14) had only very small nematodes in histological sections of brain and virtually no encephalitis, suggesting early infection. I mmature L3 only were recovered from bats 3 and 4, and all three flying foxes were killed within 24 hours of being found. It appears these three flying foxes presented with acute, severe disease just 1 to 3 days after infection. Bat 6 also appears 
to have been found only 1 to 2 days after infection, but survived in care for as long as 22 days. The remainder $(n=9)$ appear to have been found, unable to fly, 9 to 27 days after infection, and died or were killed 14 to 34 days after infection. Bat 11, the captive-born juvenile, appears to have been infected shortly after release. Bat 13 had a particularly intense exposure, with 43 worms recovered from half the brain, yet this bat appears to have been infected for 20 days before being found, and survived a further 7 days in care before being killed. There seems to be no correlation between the number of worms recovered (per half-brain) and either the estimated interval after infection when found, or the duration of infection before death. These estimates suggest that most bats become affected and cannot fly 1 to 3 weeks after infection. T his parallels human infections: in one well-documented outbreak in a group of men, several developed neurological symptoms as early as 1 to 2 days after exposure, whereas most were hospitalised within 1 to 2 weeks of the onset of symptoms. ${ }^{10}$

I deally, finding worms in the right ventricular outflow would require fresh tissue for careful dissection of the heart and pulmonary arterial tree, but all heart and lung samples had been fixed. Branches of the major pulmonary arteries were considered most likely to harbor adult worms, yet none was found in transverse sections of the pulmonary hilar region, suggesting that A cantonensis had not migrated beyond the CNS. T he lungs of infected aberrant hosts are rarely examined specifically for the presence of adult worms, but when this parasite has been found in human lungs, it has been in cases with heavy and prolonged infections. 11,12 The ability of Angiostrongylus to reach the lungs and develop further probably varies with the host species.

Of the 16 recent cases, eight were found on the ground, six were found hanging inappropriately low in a tree and unable to fly away, and two were rescued from fences. The clinical picture was dominated by paresis, particularly of the hind limbs, and depression. Bat 3, which had severe hindlimb paralysis and incontinence, was shown radiologically to have a fractured lumbar vertebra. Presumably, this flying fox had been predisposed to an accident by infection with Angiostrongylus $L 3$, and the clinical presentation reflected both the spinal fracture and neuro-angiostrongylosis. W hereas six flying foxes died or were killed the day they were found, 11 of the 17 cases survived in the care of voluntary wildlife carers for variable periods: 3 days $(n=3), 7$ to 9 days $(n=5)$ and $>15$ days $(n=3)$. Their histories and initial clinical signs closely resemble cases of Australian bat lyssavirus infection ${ }^{13,14}$ (J Barrett, unpublished observations). Given the difficulty of distinguishing angiostrongylosis from Australian bat lyssavirus infection on clinical signs, the risks associated with caring for bats infected with Australian bat lyssavirus, ${ }^{15}$ and the poor prognosis of both diseases, wildlife carers should be urged not to care for flying foxes with neurological disease, but to submit them for lyssavirus testing.

\section{Acknowledgments}

This work would not have been possible without the contributions of many individuals. Especially appreciated are wildlife carers H elen G ormley, Janet Bronk, Louise Saunders, Janiene Dury and Helen Younghusband, of O rphan $\mathrm{N}$ ative Animal Rear and Release Association Inc (O N ARR), and veterinarians Jon $\mathrm{H}$ anger of W ildcare, N erang, Janet D onovan of Clontarf, Vere N icholson and Steve Unwin of Currumbin Sanctuary, Vicki Barker of N ambour Veterinary Surgery, and H ume Field and $\mathrm{Kim} \mathrm{H}$ alpin of the Animal Research Institute, Yeerongpilly, for submitting flying foxes and providing clinical histories and observations. Roger Kelly, of the School of Veterinary Science at The University of Q ueensland provided archival material. Barry Rodwell, of the Animal Research Institute, Yeerongpilly, performed the lyssavirus fluorescent antibody tests, $\mathrm{N}$ atasha Smith of the Animal Research Institute sampled three of the brains, and Annie Rose and Morag W ilson of the School of Veterinary Science at The U niversity of Q ueensland, provided the spinal radiographs.

\section{References}

1. Mackerras MJ, Sandars DF. The life history of the rat lungworm, Angiostrongylus cantonensis (Chen) (Nematoda: Metastrongylidae). Aust $J$ Zool 1955;3:1-25.

2. Prociv P, Spratt DM, Carlisle MS. Neuro-angiostongyliasis: unresolved issues. Int J Parasitol 2000;30:1295-1303.

3. Reddacliff LA, Bellamy TA, Hartley WJ. Angiostrongylus cantonensis infection in grey-headed fruit bats (Pteropus poliocephalus). Aust Vet J 1999;77:466-8.

4. Bhaibulaya M. Comparative studies on the life history of Angiostrongylus mackerrasae Bhaibulaya, 1986 and Angiostrongylus cantonensis (Chen, 1935). Int J Parasitol 1975;5:7-20.

5. Bhaibulaya M. A new species of Angiostronylus in an Australian rat, Rattus fuscipes. Parasitology 1968;58:789-799.

6. Jackson ES. Comparison of the diets of urban and rural grey-headed flying foxes (Pteropus poliocephalus). [BSc Hons thesis] Department of Zoology and Entomology. The University of Queensland. 2000

7. Hall L, Richards G. Flying foxes fruit and blossom bats of Australia. Australian natural history series, Dawson TJ, series editor. University of New South Wales Press Ltd, Sydney, 2000.

8. Nelson JE. Movements of Australian flying foxes (Pteropodidae: Megachiroptera). Aust J Zool 1965;13:53-73.

9. Eby P. Seasonal movements of Grey-headed flying-foxes, Pteropus poliocephalus (Chiroptera: Pteropodidae), from two maternity camps in northern New South Wales. Wildl Res 1991;18:547-59.

10. Kliks MM, Kronenke K, Hardman JM. Eosinophilic radiculomyeloencephalitis: an angiostongyliasis outbreak in American Samoa related to ingestion of Achatina fulica. Am J Trop Med Hyg 1982;31:1114-1122.

11. Cooke-Yarborough CM, Kornberg AJ, Hogg GG, Spratt DM, Forsyth JR. A fatal case of angiostrongyliasis in an 11-month-old infant. Med J Aust 1999;170:541-3.

12. Prociv P. Parasitic meningitis [editorial]. Med J Aust 1999;170:517-8.

13. Hooper PT, Lunt RA, Gould AR et al. A new lyssavirus - the first endemic rabies-related virus recognised in Australia. Bull Inst Pasteur 1997;95:209-218. 14. Field $\mathrm{H}$, McCall $\mathrm{B}$, Barrett J. Australian bat lyssavirus infection in a captive juvenile black flying fox. Emerg Infect Dis 1999;5:438-440.

15. McCall B, Epstein J, Neill A et al. Potential human exposure to Australian bat lyssavirus, Queensland, 1996-1999. Emerg Infect Dis 2000;6:259-264.

(Accepted for publication 27 February 2002) 